narily practised-that is to say, by menns of the various forms of oral and naso-oral inbalers, which are manufactured and noed by thousinds, and its object was to prove whether this mode of inhalation was elficient or not, I showed by experiment, what cortainly was not generally known, or the method would not have been so extensively employed, that, the greater portion of the more powerful autiseptics used was retained by the sponge, so little being unaccounted for that the conclusion seemed warranted that this method of inhalation was very ineflicient, if not without value. I purposely refrained from discusing other moles of inhalation, as by apray or steam; these I hope to refer to later on, but I think it questionable how far a steam inhaler is likely to prove beneficial in certain divenzes, not of the throat, but of the lungs themselves, even although, as in the case of Dr. Lee's steam draft inhaler, the temperature can, it is affirmed, be regulated from $75^{\circ}$ to $120^{\circ} \mathrm{F}$.

I remain, Sir, yours obediently,

June 13th, 1883. Árthur Hill HAssall, M.D. Lond.

\section{INTERNATIONAL EXHIBITION AT NICE.}

\section{To the Editor of TIIE LANCET.}

Sir, - Following the example of so many other cities, the mayor and municipality at Nics have resolved on opening an Interoational Exhibition in that city in December next. The Society of Medicine at once seized the opportunity to point out the importance of devoting a portion of the building to a Medical and Sanitary Exhibition, and you will see by the catalogue how earnestly they seek that it shall be as complete and as practic ally useful as possible. All of us who have lived on the Continent know how far from perfect are the hygienic and sauitary arrangements of our neigrbours on the other side of the Chamuel, and the Riviera has had in th-se respects more even than its fuir share of blame. If you, Sir, and other members of the profession will lend your inflience and help to promote its succes, the Medical and Sanitary Exhibition at Nice may be the starting-point of far better things thin exist at present, and we may then send our patients south in search of health with no more of those misgivingy as to imperfect drainage, uutrapped closets, and ill ventilated hou-es, which make us sometimes hesitate whether an Engli-h winter, with its damp and cold and darknesa, nay not, after all, be safer than the cloudless sky and brilliant sunahine of the Mediterranean. The ayents for Eugland are Messrs. Johnson, Castle street, Holborn, E.C., to whom all applications for space must be made, and from whom all informatiun can be obtained. I shall also be most happy to answer any inquiries on the subject.

I am, Sir, yours fauthfully,

Bolton-row, Mayfair, W., June 11th, 1883. Crinilis West.

\section{"IS SCARLATINA EVOLVED FROM DIPHTHERIA?"}

To the Editor of THE LANCET.

Sir,-As Dr. Clement Dukes's explanation of the facts noted by Dr. Meredith is insufficient to account for at least one of the classes of cases into which those involving the above question may be divided, I may be permitted to refer to a paper in vol. xvii. of St. Bartholomew's Hospital Reports, 1881, in which the subject is discussed and a case recorded. When a person contracts diphtheria after exposure to scarlatinal infection, Dr. Dukes assumes that he has been protected from the latter by a previous attack. When scarlatina follows upon exposure to diphtheria Dr. Dukes assumes the diphtheria patient to be a fomes of scarlet fever, protected from the propagation of the virus in his own body by the action of some previous attack of the disease, but capable of conveying it to others not so protected. With regard to the latter class of cases, to which those of Dr. Meredith belong, it is expressly stated in that gentleman's paper that no scarlet fever had occurred in the neighbourbood for many months and that he had taken care to ascertain the probabie absence of its operation on his patients. In a brief search through a few English periodicals, I found but one case of this kind recorded, but there were several in which a membranous pharyngitis or diphtheria had followed the exposure to scarlatinal poison of persons who had never suffered from the latter disease. And the conclusion I arrived at from these and frum the cases under my own observation was, that a person who had never had scarlet fever might by exposure to its infection suffer from membranous pharyngiti in the entire absence of the ordinary symptoms of the fever. June 4th, 1883. I am, sir, yours truly,

DAVID A. KING,

\section{To the Editor of THE LANCET.}

SrR,-A short time since I was requested to visit a gentle. man who was ill with throat affection. Upon examination it was found to be diphtheria of an acute character, the whole of the $f_{a}$ uces boing lined with the dense parchment-like mem. brane so characteristic of this malady. Iron with quinine and chlorate of potash were administered, a supporting diet ordered, with port wine, and the usual antiseptic appliances used. At the expiration of about a week the membrane became completely detached and the rash of scarlatina became mani. fest thoughout the whole surface of the body. This passel through its usual course, followed by desquamation of the cuticle. The same treatment was continued throughout, and in due time the patient became convalescent, although the nervous system was for some period depressed from the iufluence of the poison that had been set up. The case ras a severe one, the age being twenty and the health, in general good. I have been induced to forward the above as, in las week's LaNCET, the question was asked, "Is scarlatina evolved from diphtheria?"

I remain, Sir, yours truly,

SPENCER J. SMYTH, M.D., \&.

Forest Hill, S.E., June 2nd, 1883.

\section{ON S UGAR-TESTING.}

To the Editor of THE LAXCET.

SIR,-Dr. Oliver's communication of last week on this subject induces me to mention some observations on the picrate of potash test for grape sugar made by Mr, Gibson, a friend who frequently works along with me, and myself.

That this test is affected by something in the urine other than grape sugar is $\epsilon$ vident from the following fact. When we mix eighty minims of a solution of glucose with thirty of liquor potassæ and ten of picric acid solution, the nixture is of a pale yellow colour, and if we allow it to stand for an hour or so it becomes a little deeper, but remains yellow, If it be boiled it assumes a reddis tinge, at $70^{\circ} \mathrm{C}$, or it marbe $50^{\circ} \mathrm{C}$ if the temperature be raised somewhat slowly, When we mix normal urine, on the other hand, with the test fluids in the same proportions, the mixture becomes instantly, or in a few seconds, red without the application of heat. In a minute or so the depth of colour may be such is to indicate one-eighth of a grain of sugar to the ounce, while in half an hour in the cold, or at once if raised to $50^{\circ} \mathrm{C}$ it generally corresponds to a quarter of a grain to the ounce.

When experimenting on the so-called indican (Heller's uroxanthine) we incidentally noticed that urines containing much of this body, or bodies, reduced the alkaline picric test to a considerable extent, although they had no action on the copper test till the indican was decomposed by acids and oxidising agents. Horses' urine generally contains a considerable proportion of indican, and in five instances in which we examined it we found it to indicate halt a grain to one grain and three quarters to the ounce by the picrate test. In only one case was there a slight reaction with Febling, and this was not that which showed the maximum of sugar by the other test. The specimen which gave one grain and three-quarters to the ounce indicated at $50^{\circ} \mathrm{C}$. three-quarters of a grain to the ounce, and one-quarter of a grain in the cold. We always found the result obtained by the picrate of potash test to be in proportion to the depth of colour produced by boiling with hydrochloric acid and subsequently treating with solution of hypochlorite of lime, that is apparently in proportion to the amount of indican present. In human urine containing a considerable proportion of indican, easily recognised by becoming of a deep blue on boiling with bydrochloric acid, and forming a cha racteristic copper-like scum on the surface after standing twenty-four hours, we have also found the colonration with the test to be such as frequently to indicate one grain and a half of sugar to the ounce when no result was ob. tained with Fehling. We have seen such urines prodace 